\title{
EMERGENCY MEDICINE
}

\section{9}

\section{Treatment of Hypovolemic} Shock in Cold, Field Conditions

Pihlajaniemi $R$, * Mela $M^{* *}$

* Northern Command Headquarters

** Department of Biophysics

Oulu, Finland

Objective: The initial treatment of a wounded patient with hypovolemia necessitates rapid infusions of fluid. In cold surroundings, the infusion sets can freeze very quickly. Preventing this is not enough, since rapid cold infusions cause physiological danger to the patient. The aim of this study was to develop an infusion set and method which, in cold field conditions, will allow rapid pressure infusions of warm $\left(>20^{\circ} \mathrm{C}\right)$ fluids to the wounded. The further aim was to develop a protective sheet to prevent cooling of the wounded patient. Our objective was to find material and equipment which were simple, domestic, and inexpensive.

Methods: A plastic infusion bag was used with a ready-made infusion tube without a drop chamber. Since infusion with this system necessitated the use of a pressure cuff, a simple transparent one was developed. Measurements were made of the drop in temperature of infusion fluids, which were placed in thermal boxes both in the laboratory $\left(-40^{\circ} \mathrm{C}\right)$ and in the field. Two liters of fluid usually are sufficient for the initial treatment of shock.

Results: Laboratory and field conditions indicated that the infusion liquid was kept warm most efficiently when the plastic infusion bag $\left(+40^{\circ} \mathrm{C}\right)$ was placed inside the patient's field jacket and the infusion tube was taken to the patient's hand through his or her sleeve. In this way, the patient's own body warmth was utilized, and a separate active or passive shielding of the plastic bag or infusion set was not needed.

Of the tested cover sheets, the best proved to be a combination of three blankets. During the tests, a drop in body temperature was found. This was measured from the back of the patients who were lying on iron mesh stretchers. Therefore, the bottom of such stretchers should be well-insulated.

Conclusions: This equipment makes it possible to give warm fluid infusions in cold conditions and, at the same time, prevent the patient from cooling.

\section{0}

\section{Arctic Survival}

Falt $L$

Swedish Army Survival Unit

Karlsborg, Sweden

Factors affecting cold weather survival:

1) Accept your situation;

2) The will to live;

3) Knowledge;

4) Equipment for winter use; and

5) Emergency bivouac with a fire.

\section{5}

\section{A Model for Prediction of Protection Requirements in Cold Environments \\ Holmér I}

National Institute of Occupational Safety and Health

Solna, Sweden

Objective: This paper describes a simple mathematical model of human heat balance, which allows the assessment of thermal protection required for preservation of body heat of persons exposed to cold climates.

Methods: The model calculates various heat fluxes from the body on the basis of input values for air temperature, mean radiant temperature, air velocity, and humidity. The balance is calculated for defined levels of metabolic heat production. The output of the model is the required thermal insulation for the defined level of physiological strain. In its present version, the model uses a "comfort" level and a cooling level. However, any other level of strain can be defined easily and used by the model.

Results: Protection requirements, expressed as a thermal insulation value (clo-value) for two levels of metabolic heat production $\left(40\right.$ and $\left.50 \mathrm{~W} / \mathrm{m}^{2}\right)$, vary from $8-10$ clo at $-20^{\circ} \mathrm{C}$ to $5-6$ clo at $0^{\circ} \mathrm{C}\left(1 \mathrm{clo}=0.155 \mathrm{~m}^{2}{ }^{\circ} \mathrm{C} / \mathrm{W}\right)$. It is assumed that no wind is present. The filled zone between the lines should indicate the expected individual variation.

One major advantage with the model approach is that the predicted requirements can be matched against measured insulation values of clothing, sleeping bags, etc. Such measurements are made exclusively with a thermal mannequin, a method which is proposed as an international standard method (prEN 342).

Conclusion: Prediction of thermal insulation requirements in cold climates, and the subsequent matching of them against the measured performance of clothing, sleeping bags, etc., allows a rational assessment of the needs of measures for alleviation of cold stress of exposed persons or populations.

\section{6}

\section{Szpilman's Classification of Near-Drowning/Drowning: Analysis of 2,304 Cases in 20 Years}

Szpilman D, Amoedo AR, Toscano ML

Recuperation Center of Drowning

Fire Department of Rio de Janeiro

Rio de Janeiro, Brazil

Objective: To determine an adequate prognosis and a better treatment through a new classification of near-drowning/ drowning (ND/D).

Methods: From a total of 41,279 rescues made by lifeguards on the coast of Rio de Janeiro (between the beaches of Flamengo and Sao Conrado), representing $40 \%$ of the city's cases, 2,304 $\mathrm{ND} / \mathrm{D}$ cases were evaluated over a period of 20 years. The average age was 22.8 years $(\mathrm{SD}=11.5$ years $) ; 98.7 \%$ occurred in sea 
water; and $74.2 \%$ were men. To establish a new classification, clinical parameters such as pulmonary auscultation, consciousness level, necessity for ventilatory assistance, and cardiovascular clinical status were taken into consideration. All cases were classified by physicians in the first-aid department.

Results: The division of ND/D cases into different levels was made possible through clinical evaluation. Mortality evaluation was made within the first 12 hours of the accident. The classification presented correlation with treatment and initial prognosis.

$\begin{array}{lccc}\text { Level } & \begin{array}{c}\text { Frequency } \\ (\%)\end{array} & \begin{array}{c}\text { Mortality } \\ (\%)\end{array} & \begin{array}{c}\text { Internee } \\ (\%)\end{array} \\ \text { I } & 63.3 & 0 & 3.9 \\ \text { II } & 18.6 & 0 & 16.1 \\ \text { Illa } & 3.2 & 0 & 47.9 \\ \text { IIIb } & 2.2 & 0 & 96.0 \\ \text { IVa } & 1.3 & 3.5 & 86.2 \\ \text { IVb } & 11.5 & 93.2 & 6.4\end{array}$

Conclusion: Szpilman's classification of ND/D demonstrates significance $(p<.05)$ in all clinical parameters evaluated. Even though the hospital follow-up has not been completed, the 252 patients needing intervention (126 in ICU) represent only about $10 \%$ of these cases.

\section{7}

\section{One Year in an Emergency Medical Service in Argentina}

Muro MR, Waisbord C

Vittal Socorro Médical Privado

Buenos Aires, Argentina

Objective: To describe emergency medical services (EMS) developed in the (Argentine) system during one year.

Methods: A study was conducted of all the medical prehospital requests from June 1991 to June 1992. Different classifications were made according to: 1) dispatch codes; 2) age; 3) calling hours; 4) frequency of symptoms; 5) specificity of priority assessment; 6) incorrect triage average; and 7) percentage of patients who needed to be transported.

Results: A total of 83,029 patients received response during the described period. Seventy-four percent $(61,638)$ were associated with the system that serves 180,000 direct members; the others were distributed as indirect members, street public calls, police and fire incidents, etc. A total of 45,849 females (55\%) and $45 \%$ males requested service. Nearly $39 \%$ of those requesting services required emergency attention. The more frequent causes for service requests included:

$\begin{array}{lc}\text { Diagnosis } & \% \text { of Cases } \\ \text { Trauma } & 8.5 \\ \text { Digestive Diseases } & 6.9 \\ \text { Hypertension } & 3.1 \\ \text { Fever } & 3.1 \\ \text { Cardiac Arrest } & 1.0\end{array}$

Thirty-four percent were over 55 years of age and $30 \%$ were under age 12. Categorization was correct in $80 \%$ to Code 3 ; $60 \%$ to Code 2 ; and $43 \%$ to Code 1 . Only $15 \%$ of all the patients had to be transported to a medical center.

Conclusion: Emergency ambulance crews complained about public misuse and abuse of limited resources that demoralize the staff. Six percent of the calls received incorrect triage and were assigned a lower level of priority than was the need.

\section{9}

\section{Unexpected High Prevalence of Chlamydia pneumoniae Pneumonia in an Emergency Department in Italy}

Cosentini R, Rossi S, Randozzo A

Emergency Department, Ospedale Maggiore

Milano, Italy

Aim of the Study: To determine, by non-invasive methods, the bacterial etiology of pneumonias admitted to an Emergency Medicine Unit.

Materials and Methods: Between February and December 1992, 84 patients were admitted to this ward with communityacquired pneumonia (CAP). All subjects underwent sputum or broncho-aspirate culture, blood culture when body temperature $>38^{\circ} \mathrm{C}$, pharyngeal swab for Chlamydia pneumoniae for direct detection by an indirect immunofluorescence test (Cellabs Diagnostic PTY), and acute and convalescent serologic examination for C. Pneumoniae, (microimmunofluorescence test with specific antigen, Washington Research Foundation, Seattle, Wash., USA), L. pneumophila, and M. pneumoniae.

Results: Among the patients enrolled, 17 had no associated diseases, while 23 suffered with COPD, 17 had chronic diseases, nine were immuno-depressed, and 17 had cardiovascular diseases. Before admission, 16 patients had been treated with antibiotics. Etiologic diagnosis was found in 43 patients $(51 \%$; see Table). Only $7 \%$ showed Streptococcus p. infection, whereas $15 \%$ had C. pneumoniae infection. Gram negative infection also was common $(15 \%)$, as expected, due to the high prevalence of neoplastic and immuno-depressed patients enrolled.

$\begin{array}{lc}\text { Table-Microbiologic results } & \\ \text { Organism } & \text { Prevalence (\%) } \\ \text { Clamydia pneumoniae } & 15 \\ \text { Streptococcus pneumoniae } & 7 \\ \text { Staphylococcus aureus } & 5 \\ \text { Mycoplasma pneumoniae } & 4 \\ \text { Haemophilus influenzae } & 4 \\ \text { Legionella pneumophila } & 2 \\ \text { Klebsiella pneumoniae } & 1 \\ \text { Streptococcus faecalis } & 1 \\ \text { Enterococcus spp } & 1 \\ \text { Pneumocystis carini } & 1 \\ \text { Serratia spp } & 1 \\ \text { Branhamella catarrhalis } & 1 \\ \text { Others } & 3\end{array}$

Conclusions: C. pneumoniae is reported to be involved in about $6 \%-10 \%$ of CAP. However, it was found that an unexpected high incidence of $\mathrm{C}$. pneumoniae together with a low frequency of Streptococcus p.; this could be due, at least par- 